\title{
Adult pilocytic astrocytoma in the molecular era: a comprehensive review
}

\author{
Timothy A Gregory*,1 (D), Lyndon B Chumbley², John W Henson ${ }^{3}$ \& Brett J Theeler $4,5,6$ \\ ${ }^{1}$ Department of Medicine, Neurology, Madigan Army Medical Center, Tacoma, WA 98431, USA \\ ${ }^{2}$ University of Rochester School of Medicine \& Dentistry, University of Rochester Medical Center, Rochester, NY 14642, USA \\ ${ }^{3}$ Ben \& Catherine Ivy Center for Advanced Brain Tumor Treatment, Swedish Medical Center, Seattle, WA 98122, USA \\ ${ }^{4}$ Department of Neurology, Walter Reed National Military Medical Center, Bethesda, MD 20889, USA \\ ${ }^{5}$ John P Murtha Cancer Center, Walter Reed National Military Medical Center, Bethesda, MD 20889, USA \\ ${ }^{6} \mathrm{NIH} / \mathrm{NCI}$ Neuro-Oncology Branch, Bethesda, MD 20892-8202, USA \\ *Author for correspondence: timothy.a.gregory20.mil@mail.mil
}

Adult pilocytic astrocytoma (PA) is less prevalent than pediatric PA and is associated with a worse prognosis. In a literature review, we found that $88.3 \%$ of the molecular alterations in adult PA are associated with MAPK pathway dysregulation. The most common alterations are fusions of BRAF. Understanding of the mechanisms underlying this pathway has evolved substantially, heralding advancements in specific targeted therapy. Here, we review clinical and molecular features of adult PA, characteristics predicting aggressive behavior and approaches to standard and investigational therapies. We highlight epigenetic profiling and integrated diagnosis as an essential component of classifying PA.

First draft submitted: 15 October 2020; Accepted for publication: 3 December 2020; Published online: 15 January 2021

Keywords: adult $\bullet$ BRAF $\bullet$ MAPK pathway $\bullet$ pilocytic astrocytoma $\bullet$ targeted therapy

Pilocytic astrocytoma (PA) is a WHO (Geneva, Switzerland) grade I neoplasm with a benign course following surgical resection and a 10-year survival of approximately $95 \%[1,2]$. PA represents the most common primary CNS neoplasm in the pediatric age group (5-14 years) and 75\% of the 4969 PAs diagnosed in the US from 2012 to 2016 were diagnosed before age 20. The average annual incidence rate during this timeframe was 994 patients per year. In patients aged $0-14$, PA represents $17.8 \%$ of total primary brain tumors, compared with adults in whom it represents around $1.5 \%[3]$.

Molecular characterization of PA and targeted therapeutic approaches are rapidly evolving. This review details clinical, molecular and treatment paradigms in adult PA.

\section{Clinical features}

Adult PAs have a median age at diagnosis of 32.2 years with a slight female predominance [4]. PA incidence decreases with age with only 58 (1.9\%) of the 3066 adult PAs in the SEER study [5] and only 3 (2.4\%) of the 127 cases in an adult patient series presenting after age 60 [6]. Headache (47.5\%) or seizure $(13.9 \%)$ are the most common presentations, though a substantial portion are found incidentally (24.2\%) [4]. In a series of 747 adults, the breakdown of neuroanatomic locations of adult PA were as follows: cerebrum/lobar 29.7\%; cerebellum 26.6\%; brainstem 10.2\%; ventricle 9.5\%; spinal cord 7.9\%; optic nerve 2.5\%. This is distinct from pediatric PA where cerebellar and cerebral/lobar localization occurs in 37.4 and $18.6 \%$ of cases, respectively [5].

A population study observed a cancer-specific, 60 -month survival of $94-96 \%$ in pediatric patients, $92.3 \%$ in ages $20-39,78.6 \%$ in ages $40-59$ and $63.7 \%$ in ages $>60$ [5]. The declining survival trend with increasing age may be accounted for by comparatively higher KIAA1549-BRAF fusion (BK fusion) prevalence in pediatric PA, which is associated with a better prognosis. The largest single series to date of 127 adult patients demonstrated $13 \%$ mortality during a median follow-up of 31 months [6], exceeding that expected compared with pediatric PA. In a smaller, single institution cohort of 20 adults, the six that experienced symptomatic progression did so at a median of 16.5 months [7]. Resectability is highly correlated with tumor location and recurrence rate; significantly 


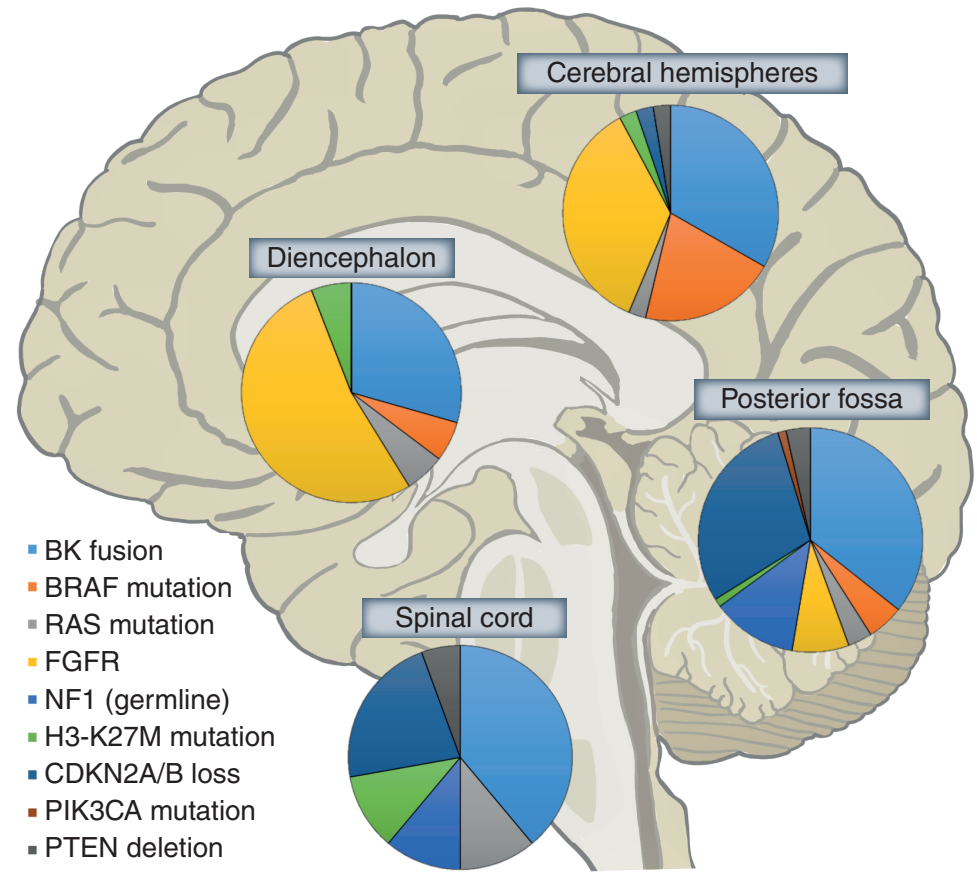

Figure 1. Summary of the relative frequency of alterations by location reported among the cases in Table 1, calculated from a total of 243 mutations in 209 adult pilocytic astrocytoma patients whose tumor location was defined.

higher recurrence rate was noted in incompletely resected (38.9\%) versus totally resected (4\%) tumors [8]. This contributes to worse prognosis in unresectable locations, such as the brainstem and diencephalon.

\section{Molecular era}

Activation of the canonical, mitogen-activated protein kinase/extracellular signal-regulated kinase (MAPK/ERK) pathway is a well-characterized driver of oncogenesis in multiple cancer types including melanoma and glioblastoma. Under nonpathologic conditions, MAPK/ERK signaling components are ubiquitous in the brain and are involved in various processes, such as memory formation, pain perception and neurogenesis. The influence of the MAPK/ERK pathway on neurogenesis is central in the differentiation of mesencephalon and metencephalon, which may be related to the frequent posterior fossa presentations in the young $[9,10]$. Across all cancer types, the most common oncogene mutations in MAPK pathway regulation affect $K R A S$ followed by $B R A F$ [11], and the most common oncogenic BRAF mutation is the valine to glutamate, or BRAFV60OE, mutation resulting in a constitutively activated kinase [12]. PA is regarded as a single-hit disease resulting from MAPK dysfunction via a variety of mechanisms, including sporadic $B R A F$ fusion in $60-70 \%$, various single amino acid alterations in the $B R A F$ gene in up to $10 \%$ [13] and inherited germline mutations of the $N F 1$ gene in approximately $15 \%$, which all lead to constitutive MAPK activation [14].

We identified 273 adult PAs in the literature with a reported genetic alteration $(\mathrm{N}=336$ alterations, Table 1$)$. $88.3 \%$ of these alterations drive the MAPK pathway. The frequency of the mutations by location is shown in Figure 1.

\section{BRAF fusions}

Focal duplication of chromosome 7q34 was reported as a frequent chromosomal abnormality in PA. The 7q34 duplication is associated with gene fusion between KIAA1549 and the BRAF oncogenes (BK fusion) [43,44]. The product for all $B R A F$ fusions is absence of an inhibitory $\mathrm{N}$-domain leading to constitutively active BRAF kinase. The BK fusion is the most common molecular event in PA across all ages, occurring in up to $68 \%$ of cases of sporadic PA [45,46]. It is more common in pediatric PA than adults and is more frequent in infratentorial PA (54 vs $32 \%$ of supratentorial). In a retrospective series of $105 \mathrm{PA}$, the fusion was observed in $79 \%$ of ages $0-10,51 \%$ of ages $11-20$, $42 \%$ of ages $21-30,30 \%$ of ages $31-40$ and $7 \%$ of those older than 40 [17]. In a series of 45 adult PA, $20 \%$ had the BK fusion [6]. The BK fusion has been associated with an improved progression-free survival (PFS) and overall better prognosis in pediatric low grade gliomas [22,47], but the impact on adult survival could not be established in two large series [6,17]. Figure 2 shows a thoracic intramedullary, nonenhancing astrocytic neoplasm with BK fusion that 
Table 1. Review of reported adult pilocytic astrocytoma genetic aberrations $(n=336)$.

\begin{tabular}{|c|c|c|c|c|c|}
\hline Study/publication & Year & Genetic events & $\mathrm{n}$ & Comments & Ref. \\
\hline Yu et al. Neurology & 2009 & BK fusion & 1 & Seven adults among 70 total PAs studied & [14] \\
\hline \multirow[t]{2}{*}{ Rodriguez et al. Acta Neuropathol. } & \multirow[t]{2}{*}{2011} & BK fusion & 13 & \multirow{2}{*}{$\begin{array}{l}51 \text { adults among } 92 \text { total PAs studied } \\
\text { two patients had coexisting BK fusion and PTEN deletion }\end{array}$} & \multirow[t]{2}{*}[15]{} \\
\hline & & PTEN deletion & 5 & & \\
\hline \multirow[t]{2}{*}{ Cin et al. Acta Neuropathol. } & \multirow[t]{2}{*}{2011} & BK fusion & 14 & $\begin{array}{l}27 \text { adults among } 125 \text { total PAs studied, noting a few } \\
\text { novel fusions in peds cases }\end{array}$ & \multirow[t]{2}{*}[16]{} \\
\hline & & BRAF mutation & 2 & One V600E and one ins598T & \\
\hline \multirow{2}{*}{$\begin{array}{l}\text { Hasselblatt et al. Neuropathol. Appl. } \\
\text { Neurobiol. }\end{array}$} & \multirow[t]{2}{*}{2011} & BK fusion & 37 & \multirow[t]{2}{*}{37 adults among 105 total PAs studied } & \multirow[t]{2}{*}[17]{} \\
\hline & & NF1 mutation & 1 & & \\
\hline Schindler et al. Acta Neuropathol. & 2011 & BRAF V600E mutation & 2 & $\begin{array}{l}22 \text { adult PAs among } 1320 \text { total nervous system tumors } \\
\text { studied }\end{array}$ & [18] \\
\hline \multirow[t]{4}{*}{ Jones et al. Nat. Genet. } & \multirow[t]{4}{*}{2013} & BK fusion & 5 & \multirow[t]{4}{*}{14 adults among 104 total PAs studied } & \multirow[t]{4}{*}{ [19] } \\
\hline & & KRAS mutation & 2 & & \\
\hline & & BRAF V600E mutation & 1 & & \\
\hline & & FGFR1 mutation & 5 & & \\
\hline Cykowski et al. J. Neurooncol. & 2013 & BK fusion & 1 & One adult among 10 total PAs studied & {$[20]$} \\
\hline Yeo et al. Clin. Neuropathol. & 2013 & BRAF V600E mutation & 1 & Case report & {$[21]$} \\
\hline \multirow[t]{4}{*}{ Theeler et al. Neuro Oncol. } & \multirow[t]{4}{*}{2014} & BK fusion & 9 & \multirow{4}{*}{$\begin{array}{l}127 \text { total adult PAs studied } \\
\text { Note: One KRAS mutation coexisted with BK fusion }\end{array}$} & \multirow[t]{4}{*}{ [6] } \\
\hline & & NF1 mutation & 5 & & \\
\hline & & RAS mutation & 4 & & \\
\hline & & PIK3CA mutation & 1 & & \\
\hline $\begin{array}{l}\text { Becker et al. J. Neuropathol. Exp. } \\
\text { Neurol. }\end{array}$ & 2015 & BK fusion & 4 & 11 adults among 69 total PAs studied & [22] \\
\hline \multirow[t]{3}{*}{ Fontebasso et al. Oncotarget } & \multirow[t]{3}{*}{2015} & BK fusion & 20 & 57 adults among 118 total PAs studied $^{\dagger}$ & \multirow[t]{3}{*}{ [23] } \\
\hline & & BRAF mutation & 4 & Two V600E, one ins598T and one K656M/T658P & \\
\hline & & FGFR1 mutation & 3 & & \\
\hline Trabelsi et al. Neurochirugie & 2015 & BK fusion & 1 & Case report & [24] \\
\hline $\begin{array}{l}\text { Orillac et al. Acta Neuropathol. } \\
\text { Commun. }\end{array}$ & 2016 & $\mathrm{H} 3-\mathrm{K} 27 \mathrm{M}$ mutation & 1 & Case report & [25] \\
\hline Strowd et al. Am. J. Med. Genet. & 2016 & NF1 mutation & 3 & Three adults among seven total PAs studied & [26] \\
\hline Pathak et al. Brain Pathol. & 2017 & BK fusion & 12 & 59 total adult PAs studied. & [27] \\
\hline & & BRAF V600E mutation & 1 & Note: One patient had both BK fusion and FGFR-TKD, & \\
\hline & & FGFR1 mutation & 7 & & \\
\hline & & FGFR-TKD duplication & 3 & & \\
\hline Lehtinen et al. BMC Cancer & 2017 & BK fusion & 1 & Two adults among four total PAs studied & [28] \\
\hline Reers et al. Clin. Neuropathol. & 2017 & H3-K27M mutation & 1 & Case report & [29] \\
\hline Ballester et al. Mol. Case Stud. & 2018 & FGFR1 mutation & 1 & Case report & {$[30]$} \\
\hline Ishida et al. Pathol. Int. & 2018 & BK fusion & 1 & Case report & [31] \\
\hline Kaley et al. J. Clin. Oncol. & 2018 & BRAF V600E mutation & 2 & Basket trial that included two PA & [32] \\
\hline Liao et al. Medicine & 2018 & BK fusion & 1 & Case report & [33] \\
\hline Morita et al. J. Neurosurg. & 2018 & H3-K27M mutation & 1 & Case report & [34] \\
\hline Reinhart et al. Acta Neuropathol. & 2018 & BK fusion & 11 & 102 anaplastic PA analyzed, 83 stratified to be MC AAP & {$[35]$} \\
\hline & & BRAF V600E mutation & 1 & of which 70 were adult & \\
\hline & & FGFR1 mut/fus & 11 & Note: 30 cases nad $>1$ alteration & \\
\hline & & NF1 mutation & 19 & & \\
\hline & & CDKN2A/B loss & 60 & & \\
\hline & & KRAS mutation & 2 & & \\
\hline $\begin{array}{l}\text { Ahn et al. J. Neuropathol. Exp. } \\
\text { Neurol. }\end{array}$ & 2019 & BK fusion & 1 & Case report & [36] \\
\hline Olar et al. Clin. Pathol. & 2019 & BK fusion & 1 & Three adults among five total PAs studied & [37] \\
\hline & & PIK3CA mutation & 1 & & \\
\hline & & PTEN deletion & 3 & (One patient had all three listed mutations) & \\
\hline $\begin{array}{l}\text { Note: Only adults identified to have gene } \\
\dagger \text { Cases previously reported by Jones et a/ } \\
\ddagger \text { Methylation class anaplastic astrocytom } \\
\text { PA: Pilocytic astrocytoma. }\end{array}$ & $\begin{array}{l}\text { aberro } \\
013[1 \\
\text { vith pil }\end{array}$ & $\begin{array}{l}\text { n each series are includec } \\
\text { excluded. } \\
\text { atures. }\end{array}$ & & & \\
\hline
\end{tabular}




\begin{tabular}{|c|c|c|c|c|c|}
\hline Study/publication & Year & Genetic events & $\mathrm{n}$ & Comments & Ref. \\
\hline \multirow[t]{5}{*}{ Rodriguez et al. Brain Pathol. } & \multirow[t]{5}{*}{2019} & BK fusion & 7 & \multirow{5}{*}{$\begin{array}{l}25 \text { adults among } 36 \text { total PAs studied } \\
\text { Five adults had mutation by sequencing, an additional } \\
\text { five adults had NF1 clinical features }\end{array}$} & \multirow[t]{5}{*}{38} \\
\hline & & $\begin{array}{l}\text { BRAF activating mutation (non } \\
\text { V600E) }\end{array}$ & 1 & & \\
\hline & & NF1 mutation & 5 & & \\
\hline & & H3-K27M mutation & 3 & & \\
\hline & & CDKN2A homozygous deletion & 3 & & \\
\hline Sievers et al. Acta Neuropathol. & 2019 & FGFR1 mutation & 1 & One adult among nine total PAs studied & [39] \\
\hline \multirow[t]{2}{*}{ Trisolini et al. J. Neurooncol. } & \multirow[t]{2}{*}{2019} & BRAF mutations & 10 & \multirow{2}{*}{$\begin{array}{l}108 \text { total adult PAs studied } \\
\text { Three BRAF V600E, six p.Thr599_Val600insThr, one } \\
\text { p.Val600_Lys601>Glu }\end{array}$} & \multirow[t]{2}{*}{40} \\
\hline & & FGFR1 mutation & 15 & & \\
\hline Chiang et al. Acta Neuropathol. & 2020 & KRAS G12R & 2 & Two adults among 23 total PAs studied & [41] \\
\hline Lucas et al. Acta Neuropathol. & 2020 & FGFR1 & 3 & Three adults among eight total PAs studied & [42] \\
\hline
\end{tabular}

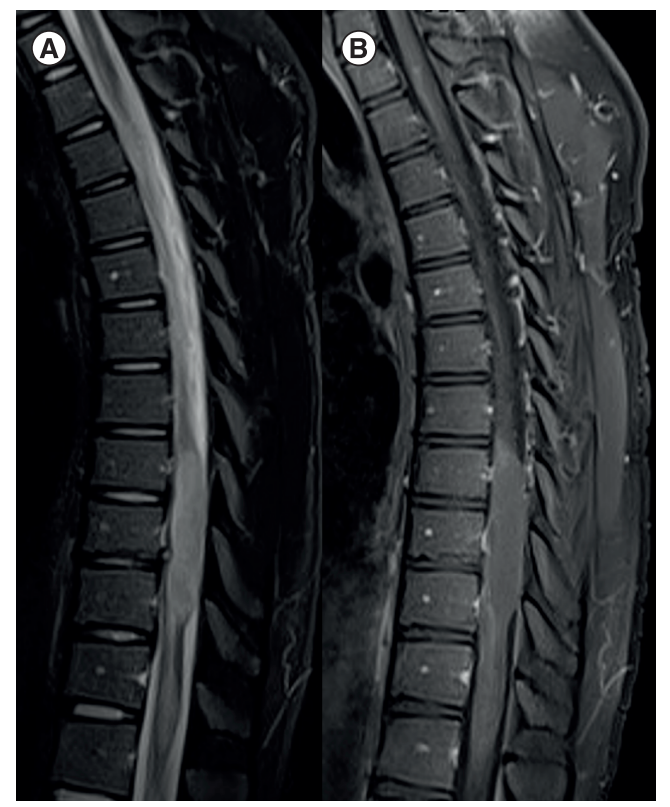

Figure 2. Spinal cord pilocytic astrocytoma with BK fusion. A 21-year old man with T2-hyperintense (A), nonenhancing (B) intramedullary thoracic lesion determined to be a pilocytic astrocytoma based on presence of KIAA1549(exon12)-BRAF(exon9) fusion.

highlights the diagnostic utility of the fusion in cases that are difficult to classify histologically. Pediatric PA with BK fusions and other Class I and II $B R A F$ mutations have both a constitutively activated MAPK pathway driving tumor growth and express markers of oncogene-induced senescence [48]. Oncogene-induced senescence may underly the unpredictable pattern of PA growth with periods of tumor growth and growth arrest. Recent characterization of mediators in the senescence-associated secretory phenotype may lead to development of predictive biomarkers and potential therapeutic targets [49]. Notably, markers of oncogene-induced senescence and the senescence-associated secretory phenotype have not been characterized in adults nor associated with the clinical outcomes in adult PA.

The list of novel $B R A F$ and $R A F$ gene fusions is continually expanding among PA and now includes FAM131BRAF, SRGAP3-RAF1, RNF130-BRAF, CLCN6-BRAF, MKRN1-BRAF and GNAI1-BRAF [16,50,51], highlighting an important area for continued investigation to characterize diagnostic, prognostic and therapeutic significance. $B R A F$ fusions are reported in multiple other glial neoplasms, including $50-77 \%$ of pilomyxoid astrocytoma, $18-21 \%$ of ganglioglioma [52,53], and in isolated cases of pleomorphic xanthoastrocytoma and ependymoma [54,55].

$B R A F$ fusions are class 2 mutations and are not responsive to first-generation BRAF inhibitors (e.g. vemurafenib); however, next generation BRAF inhibitors do appear to display preclinical activity against PA with BRAF fusions [56], which will be discussed below. The downstream effect of losing the wild-type BRAF inhibitory domain is deregulated 
MEK/ERK signaling and subsequent cell proliferation. As such, there is growing interest in utilizing MEK-inhibitors in the treatment of PA. Two cases of pediatric PA have been reported with durable symptomatic and radiographic response to trametinib, a MEK1 and MEK2 kinase inhibitor [57]. A Phase I trial of the MEK inhibitor selumetinib demonstrated a $20 \%$ sustained partial response among 38 pediatric patients with low grade glioma [58]. In association with the slow-growing nature of PAs and corresponding low Ki67 indices (generally $<5 \%$ ), the response to MEK inhibition has been noted to occur after months of treatment, suggesting activity confined to a small subset of proliferating cells [59].

\section{BRAF mutations}

The second most common mechanism of MAPK pathway dysregulation in PA is hotspot activation due to substitutions at position 600 in the BRAF gene. BRAFV600E mutations are found in approximately $50 \%$ of cutaneous melanomas $[12,60]$ and is an identified driver in a subset of colorectal cancer, non-small-cell lung cancer, papillary thyroid cancer, cholangiocarcinoma, hairy cell leukemia, multiple myeloma and Langerhans cell histiocytosis [61,62]. It is found in approximately $20 \%$ of extra-cerebellar PA and is variably associated with other CNS tumors, including $60 \%$ of (pleomorphic xanthoastrocytoma) and $20 \%$ of gangliogliomas [18]. Of the 273 adult PAs with genetic aberrations reviewed here, 9.2\% had BRAF mutations.

As a class 1 mutation, the BRAFV600-mutated kinase is a constitutively active monomer that activates downstream MEK independent of dimerization [63]. As such, BRAFV600E is a prototypical target in metastatic melanoma therapy with the widespread use of the BRAF inhibitors vemurafenib, dabrafenib and encorafenib. These are US FDA approved and improve PFS and overall survival in melanoma, though resistance to these therapies often occurs within a year [64]. Basket trials that have included high and low grade glial neoplasms have suggested a $25 \%$ response rate to vemurafenib [32]. Case reports have also noted response in BRAFV600E mutated anaplastic pleomorphic xanthoastrocytomas and gangliogliomas [65-67].

Resistance and toxicities, such as cutaneous skin lesions appear to be the result of paradoxical activation of the MAPK pathway via inhibitor bound BRAF recruitment to the plasma membrane, facilitating upregulated heterodimerization with CRAF and transactivation of MAPK activity [68]. Use in combination with a MEK inhibitor, such as trametinib, cobimetinib or binimetinib can improve clinical responses and prevent development of premalignant skin lesions; however, resistance still develops in most melanoma cases [69,70]. An anaplastic ganglioglioma that developed resistance to vemurafenib after 14 months of response was rescued by the addition of cobimetinib, producing a durable complete response 16 months after beginning the combination [71].

Several class 2, non-BRAFV600 mutations have been characterized in gliomas at undefined frequencies resulting in RAS independent dimers, unresponsive to first-generation BRAF inhibitors which only target monomers [63]. Rational means of targeting such mutations is with paradox-breaking BRAF inhibitors, such as PLX8394, which provides BRAF inhibition without promotion of dimer formation [72].

\section{NF1 \& RAS mutations}

NF1 is among the most common tumor predisposition syndromes in which neurofibromin, a negative regulator of Ras, is inactivated [73]. CNS tumors occur in up to $20 \%$ of NF1 patients, $70 \%$ of which arise along the optic pathway. Nearly all optic pathway gliomas in NF1 are PAs although clinical behavior does not significantly differ by histology. Up to two-thirds of optic pathway gliomas in children do not require therapy and some regress [26]. Higher mortality has been observed in NF1-associated gliomas when diagnosed in adulthood, occurring outside of the optic pathway or when symptomatic at discovery [26]. Up to $33 \%$ of PA with anaplasia develop in patients with a clinical diagnosis of NF1 [74], which have a more aggressive clinical course and have recurring mutations in ATRX leading to alternative lengthening of telomeres (ALT) [38].

MEK inhibition appears to be a potential target for tumor control in NF1 tumors, based on responses in neurofibromas to selumetinib. In 24 children with NF1 and treated with selumetinib, $71 \%$ had at least a $20 \%$ volume reduction, and none of the cases had tumor progression [75]. Selumetinib has been shown to have a downregulating effect on VEGF and angiogenic factors [58], corresponding to anecdotal evidence that bevacizumab can be effective against NF1-related PA. The MEK inhibitor mirdametinib has also recently demonstrated plexiform neurofibroma volume reduction in $42 \%$ of adolescent and adult Phase II subjects [76].

A low frequency of somatic KRAS mutations $(<5 \%)$ have been identified in PA [9]. In contrast with the predominant anatomic predilection of BRAF fusions (cerebellar) and BRAF V600 mutations (supratentorial) [18], somatic $R A S$ mutations seem to have a predilection for the midbrain/tectal region. A series of 23 tectal gliomas 


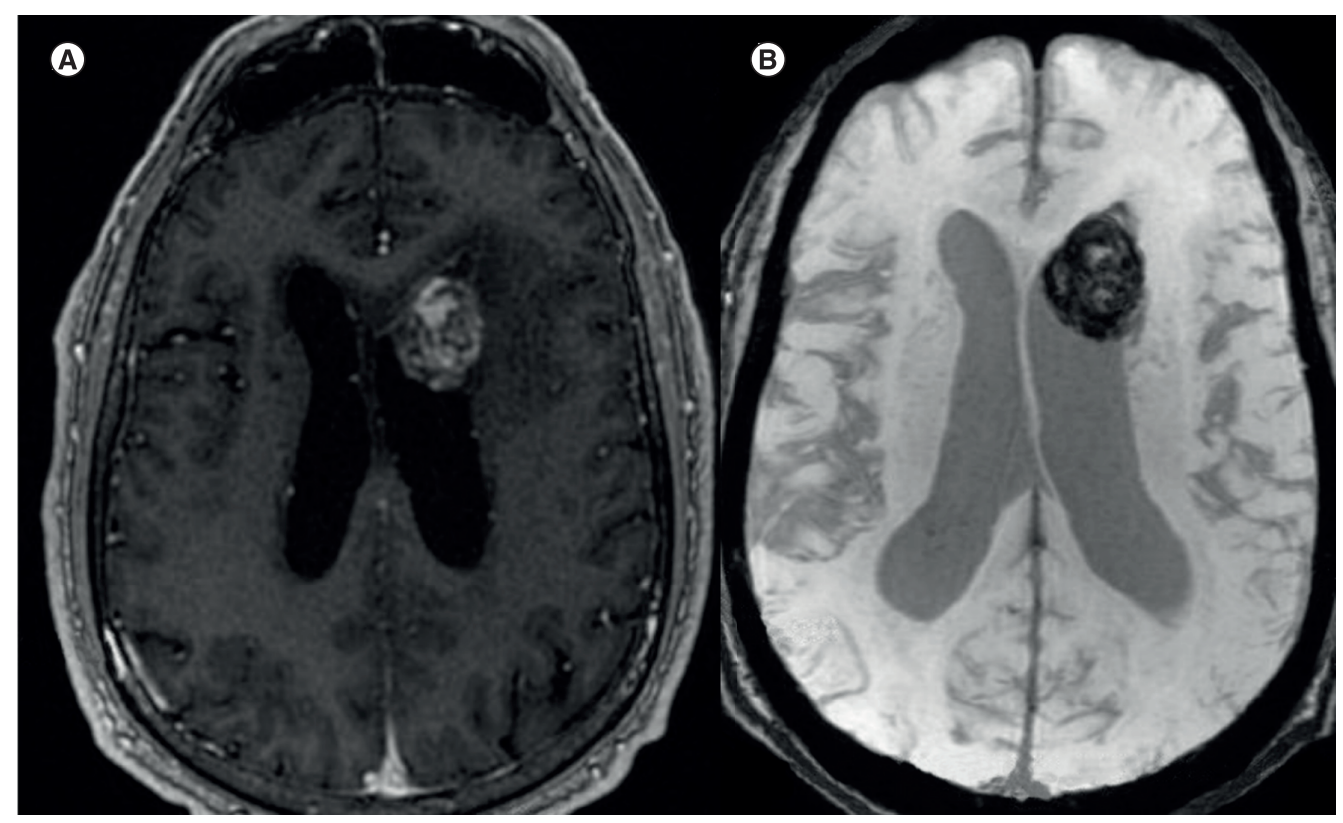

Figure 3. FGFR1-mutated pilocytic astrocytoma. Left lateral ventricular heterogeneously enhancing mass (A) with intralesional hemorrhage (B) in a 71-year old man. The lesion had pilocytic histology, FGFR1 mutations c.1059A > G and c.2032G > T with methylation class consistent with pilocytic astrocytoma.

harbored the hotspot KRAS G12R mutation in 19 patients (including 2 adults) (82.6\%) [41]. KRAS inhibitors are in development [77] and their role in targeted glioma therapy is unclear.

\section{FGFR \& other rare events}

Mutations, fusions or duplications of the upstream regulators of the MAPK pathway, including the tyrosine kinase FGFR1, can drive pathologic MAPK activation in adult PA. Duplication events and various mutations of FGFR1 have been described as a frequent occurrence in up to $60 \%$ of dysembryoplastic neuroepithelial tumors [78]. In PAs, hotspot point mutations in FGFR1 have been implicated in altered autophosphorylation and increased kinase activity [19]. FGFR1 mutations were found in 15 of a series of 108 adult PA (patients age $>15$ ) and were associated with a significantly higher prevalence among sporadic optic pathway PA (6/9) [40]. FGFR1 mutations increase in frequency in older PA patients (Figure 3) [79]. Compared with wild-type in a series of 69 PAs, the $7 \%$ of cases with FGFR1 mutation had decreased overall and event-free survival [22]. FGFR1 inhibitors, such as ponatinib and lucitanib have been utilized in other solid malignancies but their role in CNS tumors has yet to be defined. Erdafitinib is now US FDA approved for urothelial carcinoma but has unknown CNS penetrance [80], though two advanced glioblastoma patients with FGFR3-TACC3 rearrangements experienced clinical improvement [81]. A basket trial with the FGFR inhibitor, TAS-120, also includes glial neoplasms (NCT02052778).

$N T R K$ fusions have additionally been identified as a rare event involved in multiple solid malignancies, including colorectal cancer and papillary thyroid carcinoma. In a whole genome assessment of 96 PAs, three pediatric patients were found to have oncogenic NTRK fusions implicated in tumorigenesis [19]. The prevalence of this mutation in adults is unknown. NTRK fusions have demonstrated responsiveness to TRK inhibition [82] resulting in US FDA approval of larotrectinib and entrectinib for solid tumors harboring the fusion, the latter with comparatively better CNS penetration [80].

\section{High risk features of PA}

PA with anaplastic histology has been shown to behave more aggressively and portend a worse outcome. Histologic features designating an anaplastic PA include brisk mitotic activity (at least 5 mitoses per 10 high power fields), hypercellularity, cytologic atypia with or without necrosis, in an otherwise well-circumscribed, noninfiltrative lesion [38]. Rodriguez et al. have recently demonstrated that the majority of PA with anaplasia harbor ALT (69\%) and ATRX loss (57\%); this included a significant proportion of NF1 patients. In addition to MAPK activation, 
dysregulation of the PI3K/Akt pathway has been reported in clinically aggressive and anaplastic PA, with the majority of PA with PI3K/Akt activation being of adult age [37,74] Anaplasia was found to herald a worse prognosis with median overall survival of 13 months [38]. In a recent retrospective series of 102 anaplastic PA, 83 cases (89\% adults) clustered into a novel methylation class designated anaplastic astrocytoma with piloid features [35], leading to cIMPACT's recent recognition of high-grade astrocytoma with piloid features as a distinct entity [83]. High-grade astrocytoma with piloid features has been associated with MAPK pathway gene alterations in $75 \%$ and $C D K N 2 A / B$ deletion in $80 \%$ [35]. $C D K N 2 A / B$ deletion is similarly strongly associated with poor survival outcomes in IDH-mutated glioma [84]. H3-K27M has been implicated in development of anaplastic histology and aggressive behavior in circumscribed, nondiffuse glioma [85]. Though generally regarded as a defining mutation in grade IV diffuse midline gliomas, three case reports of less aggressive adult PA harboring H3-K27M mutations imply that this mutation may not have the same prognostic significance in PA $[25,34,86]$. Aneuploidy, most frequently involving chromosomes 5, 7, 6 and 11, preferentially affects adult compared with pediatric PA (45 vs 17\%), and is typically found in noncerebellar and non-BK fusion cases, suggesting another possible driver for worsened outcome in adults [23].

Histology consistent with pilomyxoid astrocytoma, which predominantly arises in younger patients and in the hypothalamic/chiasmatic region, is noted to be independently associated with a more aggressive course and decreased overall survival, in part due to a propensity for leptomeningeal seeding [87]. At least half of these tumors are associated with BK fusion [53] and the known tendency for pilomyxoid astrocytoma to mature into PA suggests these are the same entity existing together on a spectrum [88]. Similarly, diffuse leptomeningeal glioneuronal tumor demonstrates a high rate of BK fusion in up to $75 \%$ [89], and a subset of these (up to 22\%) can demonstrate anaplastic progression with worsened outcome [15]. Despite its nomenclature, multiple cases of focal, circumscribed parenchymal tumor have resolved to diffuse leptomeningeal glioneuronal tumor on methylome analysis [90], making the classification of this entity unclear. Epigenetic analysis is further aiding the delineation of rosette-forming glioneuronal tumor from PA and other low grade neuroepithelial tumors with overlapping genomic signatures, with recent description of FGFR1 p.N546 or p.K656 mutation with PIK3CA or PIK3R1 appearing to represent a molecular signature specific to rosette-forming glioneuronal tumor [42].

Histologically benign PAs and glioneuronal tumors sometimes reclassify to other tumor types when DNA methylation profiling is employed, including to more aggressive tumors such as high-grade astrocytoma with piloid features [91,92]. Conversely, 5\% of 160 glioblastomas were reclassified as a lower grade entity, including multiple gangliogliomas and at least one PA [93], highlighting that challenging histologic cases may require further differentiation with DNA methylation profiling. In summary, aggressive behavior is at least in part mediated by molecular factors that need to be defined in the context of clinical, histomorphological, genetic and epigenetic factors. An integrated diagnosis including histology, mutational profile and methylome profile is emerging as the most accurate way to identify and differentiate PAs with anaplastic features from other high-grade CNS neoplasms.

\section{Treatment}

\section{Standard therapies}

Gross total resection, the mainstay of therapy, is associated with greater than 95\% 10-year survival in pediatric PA [2]. A majority of adults have favorable outcomes after gross total resection, with evidence of both improved PFS and overall survival [8], though long-term outcome is generally not as favorable as in pediatric PA. A retrospective aggregation of 254 adult patients with an average follow-up of 77 months showed a $28 \%$ rate of subsequent recurrence after gross total resection [4] compared with a recurrence rate of $10 \%$ reported in pediatric patients [94]. A watch-and-wait approach after maximal resection remains the standard of care for most adult PA patients.

Adjuvant radiation therapy (RT) was associated with significantly decreased PFS in the largest, single-center retrospective study [6] and was one of three factors associated with decreased survival in a population study of adult PA [5]. Conversely, a retrospective series of 30 adult PA showed 5- and 10-year PFS rates of 91 and 60\%, respectively, compared with 42 and 17\% without adjuvant RT [95]. A prospective series of adults that included three biopsy-only patients who underwent adjuvant RT showed no evidence of disease progression at 18.8, 16.1 and 2.1 years [96]. A 2013 review of the literature suggested that malignant transformation of PA occurs mainly in tumors treated with prior irradiation [97]. In a study of anaplastic PA with ALT and ATRX loss, nine of 15 patients in whom anaplasia arose from a precursor PA had received prior irradiation, and in a separate series of three adult anaplastic PA patients with ATRX loss, all had received prior RT, one tumor had a PIK3CA mutation, and another 


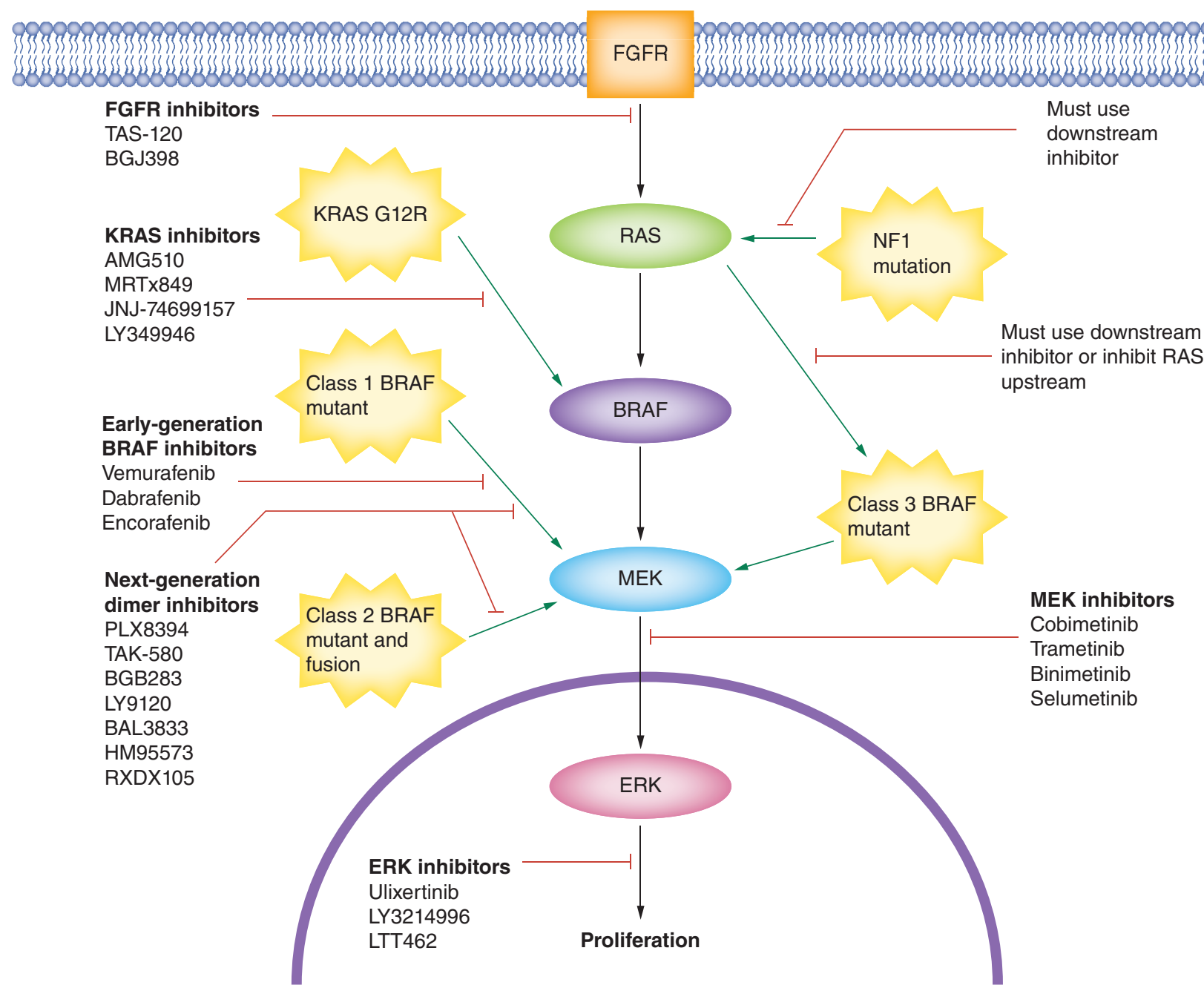

Figure 4. Overview of targetable regions of the MAPK pathway and therapies currently available or undergoing trial.

a PDGFR mutation [37,74]. Whether RT should be avoided due to deleterious impact on tumor biology in some cases, or whether RT should be employed in an adjuvant setting in cases with STR, requires prospective study.

PA does not have MGMT promotor methylation and temozolomide does not appear to be effective based on case reports and anecdote [98,99]. Platinum-based chemotherapy regimens used in pediatric low-grade gliomas, such as carboplatin and vincristine [100], may be an option in adult patients with progressive tumors but the effectiveness is unknown. Further addition of etoposide did not show benefit in a Phase III study in children, and whether adults would benefit from chemotherapy intensification is unknown [101]. Single-agent vinblastine has shown benefit in pediatric PA [102] and while not studied in adults, this may be another cytotoxic chemotherapy option for select patients. Specific examples of when pediatric chemotherapy regimens may be considered would include sporadic optic pathway PAs in young adults as a strategy to delay the need for radiotherapy. Multi-disciplinary treatment planning of adult PA patients is of paramount importance given the lack of prospective evidence to guide treatment decisions with regards to timing of radiotherapy and use of chemotherapy in the adjuvant and recurrent settings.

\section{Targeted therapies}

MAPK pathway dysregulation is central to PA oncogenesis and rational pursuit of molecular targets has become an essential quest over the past decade [43,103]. Figure 4 illustrates current and experimental therapies targeting the various components of the pathway. In short, identification of a class II or III BRAF mutation precludes the use of an early generation BRAF inhibitor, which can only target class I mutations. Class I V600E-mutant low- 


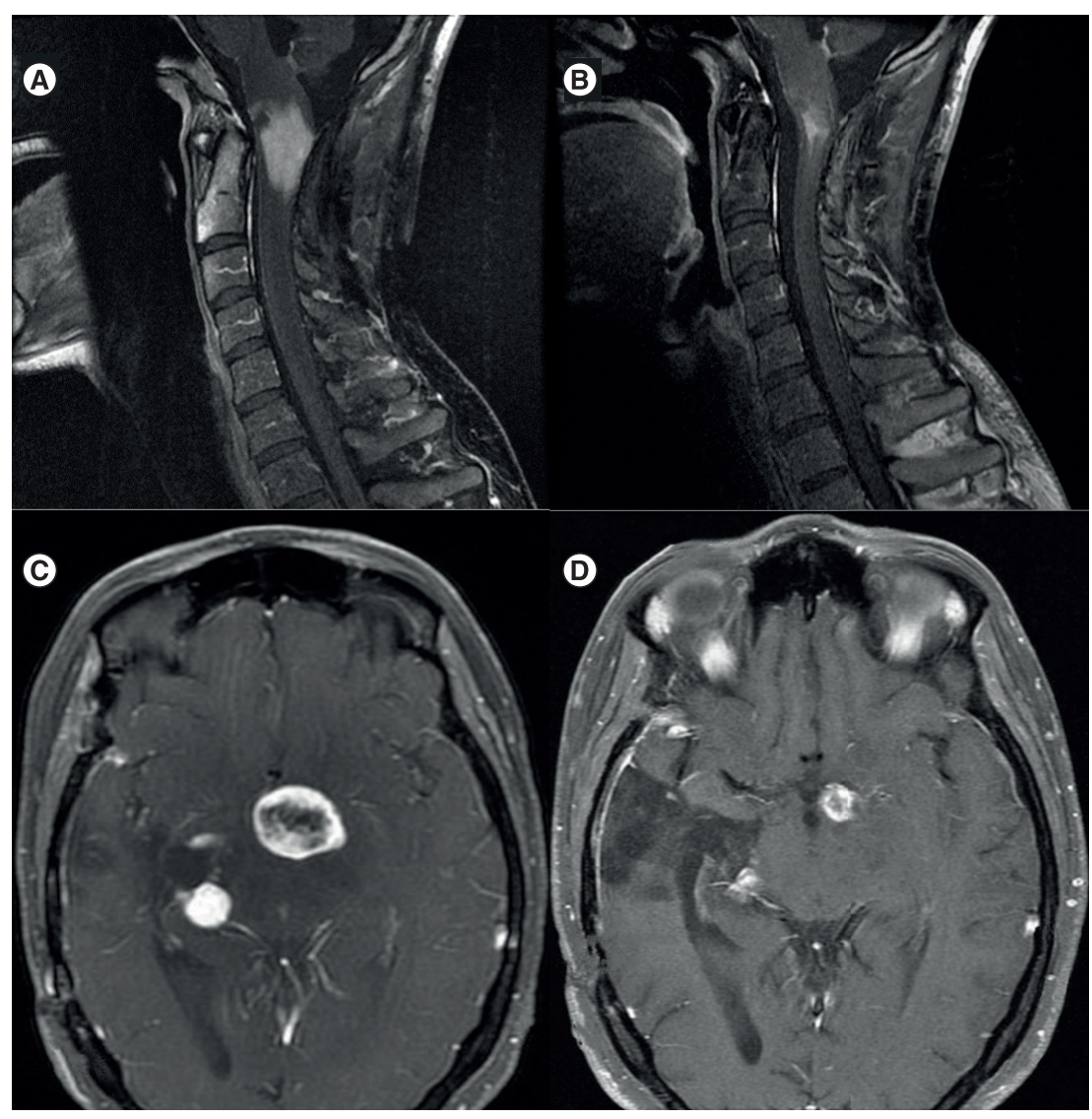

Figure 5. Responses to therapy. (A) 28-year old man with BRAFV600E-mutated pilocytic astrocytoma at the cervicomedullary junction and marked response to dual BRAF pathway inhibition with dabrafenib and trametinib at 3-month interval (B). (C) A 21-year old woman with sporadic optic pathway glioma with significant response to bevacizumab shown at 2-month interval (D).

grade glioma appear to benefit from treatment with dabrafenib in the relapsed or refractory pediatric setting [104]. Randomized trials are currently evaluating targeted therapy versus chemotherapy in pediatric low-grade gliomas, including dabrafenib plus trametinib versus carboplatin plus vincristine (NCT02684058, 18 years or younger included), selumetinib versus carboplatin plus vincristine (NCT03871257, 21 years or younger included) and trametinib versus carboplatin plus vincristine in the Phase III LOGGIC trial (18 years or younger included) [105]. Downstream MEK-inhibition is a reasonable adjunct for V600E mutants as shown in Figure $5 \mathrm{~A}$ and B, as well as for class II mutations and fusions [63]. While these strategies are limited by the lack of prospective data and understanding of resistance mechanisms in adults, MEK inhibition employed in progressive pediatric low-grade glioma has demonstrated benefit, including $100 \%$ disease control in 18 children treated with trametinib [106] and up to $40 \%$ sustained partial response in recurrent, refractory or progressive cases treated with selumetinib [107].

Currently under study are paradox-breakers, such as PLX8394, and pan-RAF kinase inhibitors, such as TAK580, which can prevent or overcome RAF dimer formation thereby circumventing paradoxical MAPK activation [108]. For NF1 mutations, downstream MEK inhibition is potentially beneficial as discussed previously. Further study is warranted to further define parallel PI3K-mTOR pathway inhibition as a strategy to overcome resistance to BRAF/MEK inhibition, with some suggested benefit of this approach in a series of five V600-mutated gliomas employing vemurafenib combined with everolimus [109]. Questions that often come up in multi-disciplinary discussion include the optimal timing of off-label, targeted therapy whether in an adjuvant setting, before or after radiation at recurrence, or as monotherapy for recurrent disease.

Bevacizumab also appears to be beneficial based on small studies. In an 11-patient adult series using bevacizumab alone in four patients or with temozolomide in seven patients with unresectable PA, all but one achieved a partial response [110]. A more recent series of four adults demonstrated significant clinical and radiographic response, 
including two complete responses, which were durable across follow-up that ranged from 7 to 37 months [111]. These correspond with a retrospective series of high grade gliomas in five adult NF1 patients, at least two of which may have represented transformed PA, which showed postrecurrence response to bevacizumab ranging from 10 to 72 months [112]. Figure 5C and D shows a sporadic optic pathway PA in an adult patient that had a durable response to bevacizumab after failing radiotherapy and cytotoxic chemotherapy at recurrence.

\section{Future perspective}

Future directions include synthesis of histologic, molecular and epigenetic data to personalized therapeutic approaches in adult PA. Prospective clinical data will be difficult to obtain due to tumor rarity and multi-institution cooperation, for example with use of registries, will be needed. The variety of targeted therapeutics undergoing investigation foretells an expanding range of therapeutic options, but determining the optimal targets, use of single versus multiple targeted agents and the timing of targeted therapeutics will require innovative clinical research efforts in adult PA.

\section{Executive summary}

- Adult pilocytic astrocytoma (PA) represents approximately $25 \%$ of all PAs and are associated with inferior survival outcomes compared with pediatric PA.

- In adult PA, MAPK alterations are the most common genomic alterations reported in the literature.

- BK fusions are the most common MAPK alteration, but the prevalence of BK fusion is lower in adult than pediatric cases and the association with survival outcomes in adults is unknown.

- BRAF, NF1 and FGFR1 mutations are additional well-characterized drivers of MAPK signaling in adult PA.

- Transformation of PA to an aggressive cancer can occur as recognized by the newly described entity, high-grade astrocytoma with piloid features.

- Markers of aggressive behavior include anaplasia, alternative lengthening of telomeres and ATRX loss, $C D K N 2 A / B$ deletion and aneuploidy.

- Integrated diagnosis improves accuracy in distinguishing entities with morphological and molecular features that overlap PA, such as pleomorphic xanthoastrocytoma, pilomyxoid astrocytoma, diffuse leptomeningeal glioneuronal tumor or rosette-forming glioneuronal tumor. Some high grade or difficult to classify glial neoplasms may be re-classified as PA with an integrated diagnostic approach including DNA methylation profiling.

- Resection is the cornerstone of adult PA therapy, with possible individualized roles for chemotherapy, radiation or bevacizumab.

- Targeting the MAPK pathway is evolving as a treatment option for some adult PA patients.

- Off label use of first-generation BRAF and MEK inhibitors may be an option for carefully selected patients.

- Future testing of the next generation of MAPK-targeted therapies will require coordinated clinical research efforts.

\section{Author contributions}

TA Gregory is the primary author. LB Chumbley contributed toward editing and figures. JW Henson contributed toward editing and figures. BJ Theeler contributed toward drafting and editing.

\section{Acknowledgments}

The authors thanked J Luizzi, I Mora-Shafer and J Ring for assistance with literature search.

\section{Financial \& competing interests disclosure}

The authors have no relevant affiliations or financial involvement with any organization or entity with a financial interest in or financial conflict with the subject matter or materials discussed in the manuscript. This includes employment, consultancies, honoraria, stock ownership or options, expert testimony, grants or patents received or pending, or royalties.

No writing assistance was utilized in the production of this manuscript.

\section{Disclaimer}

The views expressed in this article are those of the authors and do not necessarily reflect the official policy or position of the Department of the Army, Department of Defense nor the US Government. 


\section{Open access}

This work is licensed under the Attribution-NonCommercial-NoDerivatives 4.0 Unported License. To view a copy of this license, visit http://creativecommons.org/licenses/by-nc-nd/4.0/

\section{References}

Papers of special note have been highlighted as: $\bullet$ of interest; $\bullet \bullet$ of considerable interest

1. Louis DN, Perry A, Reifenberger G et al. The 2016 World Health Organization classification of tumors of the central nervous system: a summary. Acta Neuropathol. 131(6), 803-820 (2016).

2. Burkhard C, Di Patre P-L, Schüler D et al. A population-based study of the incidence and survival rates in patients with pilocytic astrocytoma. J. Neurosurg. 98(6), 1170-1174 (2003).

3. Ostrom QT, Cioffi G, Gittleman H et al. CBTRUS statistical report: primary brain and other central nervous system tumors diagnosed in the United States in 2012-2016. Neuro Oncol. 21(Suppl. 5), v1-v100 (2019).

4. Bond KM, Hughes JD, Porter AL, Orina J, Fang S, Parney IF. Adult pilocytic astrocytoma: an institutional series and systematic literature review for extent of resection and recurrence. World Neurosurg. 110, 276-283 (2018).

5. Johnson DR, Brown PD, Galanis E, Hammack JE. Pilocytic astrocytoma survival in adults: analysis of the Surveillance, Epidemiology, and End Results Program of the National Cancer Institute. J. Neurooncol. 108(1), 187-193 (2012).

-• This is the key epidemiologic study of adult pilocytic astrocytoma (PA). Shows declining survival outcomes in PA with age and use of radiotherapy.

6. Theeler BJ, Ellezam B, Sadighi ZS et al. Adult pilocytic astrocytomas: clinical features and molecular analysis. Neuro Oncol. 16(6), 841-847 (2014).

- This is the largest, single institution study of adult PA. This study found the BK fusion in $20 \%$ of adult PA cases.

7. Ellis JA, Waziri A, Balmaceda C, Canoll P, Bruce JN, Sisti MB. Rapid recurrence and malignant transformation of pilocytic astrocytoma in adult patients. J. Neurooncol. 95(3), 377-382 (2009).

8. Mair MJ, Wöhrer A, Furtner J et al. Clinical characteristics and prognostic factors of adult patients with pilocytic astrocytoma. J. Neurooncol. 148(1), 187-198 (2020).

9. Jones DTW, Gronych J, Lichter P, Witt O, Pfister SM. MAPK pathway activation in pilocytic astrocytoma. Cell. Mol. Life Sci. 69(11), 1799-1811 (2012).

10. Sato T, Nakamura H. The Fgf8 signal causes cerebellar differentiation by activating the Ras-ERK signaling pathway. Development 131(17), 4275-4285 (2004).

11. Zehir A, Benayed R, Shah RH et al. Mutational landscape of metastatic cancer revealed from prospective clinical sequencing of 10,000 patients. Nat. Med. 23(6), 703-713 (2017).

12. Davies H, Bignell GR, Cox C et al. Mutations of the BRAF gene in human cancer. Nature 417(6892), 949-954 (2002).

13. Brokinkel B, Peetz-Dienhart $S$, Ligges $S$ et al. A comparative analysis of MAPK pathway hallmark alterations in pilocytic astrocytomas: age-related and mutually exclusive. Neuropathol. Appl. Neurobiol. 41(2), 258-261 (2015).

14. Yu J, Deshmukh H, Gutmann RJ et al. Alterations of BRAF and HIPK2 loci predominate in sporadic pilocytic astrocytoma. Neurology 73(19), 1526-1531 (2009).

15. Rodriguez FJ, Perry A, Rosenblum MK et al. Disseminated oligodendroglial-like leptomeningeal tumor of childhood: a distinctive clinicopathologic entity. Acta Neuropathol. 124(5), 627-641 (2012).

16. Cin H, Meyer C, Herr R et al. Oncogenic FAM131B-BRAF fusion resulting from $7 \mathrm{q} 34$ deletion comprises an alternative mechanism of MAPK pathway activation in pilocytic astrocytoma. Acta Neuropathol. 121(6), 763-774 (2011).

17. Hasselblatt M, Riesmeier B, Lechtape B et al. BRAF-KIAA1549 fusion transcripts are less frequent in pilocytic astrocytomas diagnosed in adults: BRAF-KIAA1549 fusion transcripts in pilocytic astrocytoma. Neuropathol. Appl. Neurobiol. 37(7), 803-806 (2011).

- This is the first study which shows the indirect relationship between patient age and the BK fusion in PA patients.

18. Schindler G, Capper D, Meyer J et al. Analysis of BRAF V600E mutation in 1,320 nervous system tumors reveals high mutation frequencies in pleomorphic xanthoastrocytoma, ganglioglioma and extra-cerebellar pilocytic astrocytoma. Acta Neuropathol. 121(3), 397-405 (2011).

19. Jones DTW, Hutter B, Jäger N et al. Recurrent somatic alterations of FGFR1 and NTRK2 in pilocytic astrocytoma. Nat. Genet. 45(8), 927-932 (2013).

20. Cykowski MD, Allen RA, Kanaly AC et al. The differential diagnosis of pilocytic astrocytoma with atypical features and malignant glioma: an analysis of 16 cases with emphasis on distinguishing molecular features. J. Neurooncol. 115(3), 477-486 (2013).

21. Yeo YH, Byrne NP, Counelis GJ, Perry A. Adult with cerebellar anaplastic pilocytic astrocytoma associated with BRAF V600E mutation and p16 loss. Clin. Neuropathol. 32(3), 159-164 (2013).

22. Becker AP, Scapulatempo-Neto C, Carloni AC et al. KIAA1549: BRAF gene fusion and FGFR1 hotspot mutations are prognostic factors in pilocytic astrocytomas. J. Neuropathol. Exp. Neurol. 74(7), 743-754 (2015). 
23. Fontebasso AM, Shirinian M, Khuong-Quang D-A et al. Non-random aneuploidy specifies subgroups of pilocytic astrocytoma and correlates with older age. Oncotarget 6(31), 31844-31856 (2015).

24. Trabelsi S, Mama N, Ladib M et al. Adult recurrent pilocytic astrocytoma: clinical, histopathological and molecular study. Neurochirurgie 61(6), 392-397 (2015).

25. Orillac C, Thomas C, Dastagirzada Y et al. Pilocytic astrocytoma and glioneuronal tumor with histone H3 K27M mutation. Acta Neuropathol. Commun. 4(1), 84 (2016).

26. Strowd RE, Rodriguez FJ, McLendon RE et al. Histologically benign, clinically aggressive: progressive non-optic pathway pilocytic astrocytomas in adults with NF1. Am. J. Med. Genet. A 170(6), 1455-1461 (2016).

27. Pathak $\mathrm{P}$, Kumar A, Jha $\mathrm{P}$ et al. Genetic alterations related to BRAF-FGFR genes and dysregulated MAPK/ERK/mTOR signaling in adult pilocytic astrocytoma: genetic alterations in adult pilocytic astrocytoma. Brain Pathol. 27(5), 580-589 (2017).

28. Lehtinen B, Raita A, Kesseli J et al. Clinical association analysis of ependymomas and pilocytic astrocytomas reveals elevated FGFR3 and FGFR1 expression in aggressive ependymomas. BMC Cancer 17(1), 310 (2017).

29. Reers S, Krug D, Stummer W, Hasselblatt M. Malignant progression of a histone H3.3 K27M-mutated spinal pilocytic astrocytoma in an adult. Clin. Neuropathol. 36(2), 83-85 (2017).

30. Ballester LY, Penas-Prado M, Leeds NE, Huse JT, Fuller GN. FGFR1 tyrosine kinase domain duplication in pilocytic astrocytoma with anaplasia. Mol. Case Stud. 4(2), a002378 (2018).

31. Ishida $Y$, Tsuda M, Sawamura Y et al. "Integrated diagnosis" of pilocytic astrocytoma: molecular diagnostic procedure for an unusual case. Pathol. Int. 68(12), 694-699 (2018).

32. Kaley $\mathrm{T}$, Touat $\mathrm{M}$, Subbiah V et al. BRAF inhibition in $B R A F^{\mathrm{V} 600}$-mutant gliomas: results from the VE-BASKET study. J. Clin Oncol. 36(35), 3477-3484 (2018).

33. Liao J-M, Wang W, Xie J, Wu H-B. Dysembryoplastic neuroepithelial tumor-like pilocytic astrocytoma: a case report. Medicine (Baltimore). 97(20), e10755 (2018).

34. Morita S, Nitta M, Muragaki Y et al. Brainstem pilocytic astrocytoma with H3 K27M mutation: case report. J. Neurosurg. 129(3), 593-597 (2018).

35. Reinhardt A, Stichel D, Schrimpf D et al. Anaplastic astrocytoma with piloid features, a novel molecular class of IDH wildtype glioma with recurrent MAPK pathway, CDKN2A/B and ATRX alterations. Acta Neuropathol. 136(2), 273-291 (2018).

- This multi-institution case series defines a new entity, anaplastic astrocytoma with piloid features, which may lead to future change to the WHO Classification of PA.

36. Ahn JS, Harrison W, Hughes E, McLendon RE. Intraventricular pilocytic astrocytoma with KIAA1549/BRAF fusion arising in a 44-year old. J. Neuropathol. Exp. Neurol. 78(2), 187-190 (2019).

37. Olar A, Tran D, Mehta VP et al. ATRX protein loss and deregulation of PI3K/AKT pathway is frequent in pilocytic astrocytoma with anaplastic features. Clin. Neuropathol. 38(2), 59-73 (2019).

38. Rodriguez FJ, Brosnan-Cashman JA, Allen SJ et al. Alternative lengthening of telomeres, ATRX loss and H3-K27M mutations in histologically defined pilocytic astrocytoma with anaplasia. Brain Pathol. 29(1), 126-140 (2019).

-• This study was among the first to define high-risk molecular alterations in PAs with anaplasia.

39. Sievers P, Schrimpf D, Stichel D et al. Posterior fossa pilocytic astrocytomas with oligodendroglial features show frequent FGFR1 activation via fusion or mutation. Acta Neuropathol. 139(2), 403-406 (2020).

40. Trisolini E, Wardighi DE, Giry M et al. Actionable FGFR1 and BRAF mutations in adult circumscribed gliomas. J. Neurooncol. 145(2), 241-245 (2019).

41. Chiang J, Li X, Liu APY, Qaddoumi I, Acharya S, Ellison DW. Tectal glioma harbors high rates of KRAS G12R and concomitant KRAS and BRAF alterations. Acta Neuropathol. 139(3), 601-602 (2020).

42. Lucas C-HG, Gupta R, Doo P et al. Comprehensive analysis of diverse low-grade neuroepithelial tumors with FGFR1 alterations reveals a distinct molecular signature of rosette-forming glioneuronal tumor. Acta Neuropathol. Commun. 8(1), 151 (2020).

43. Pfister S, Janzarik WG, Remke M et al. BRAF gene duplication constitutes a mechanism of MAPK pathway activation in low-grade astrocytomas. J. Clin. Invest. 118(5), 1739-1749 (2008).

44. Sievert AJ, Jackson EM, Gai X et al. Duplication of 7q34 in pediatric low-grade astrocytomas detected by high-density single-nucleotide polymorphism-based genotype arrays results in a novel BRAF fusion gene. Brain Pathol. 19(3), 449-458 (2009).

45. Bar EE, Lin A, Tihan T, Burger PC, Eberhart CG. Frequent gains at chromosome 7q34 involving BRAF in pilocytic astrocytoma. J. Neuropathol. Exp. Neurol. 67(9), 878-887 (2008).

46. Jones DTW, Kocialkowski S, Liu L et al. Tandem duplication producing a novel oncogenic BRAF fusion gene defines the majority of pilocytic astrocytomas. Cancer Res. 68(21), 8673-8677 (2008).

47. Hawkins C, Walker E, Mohamed N et al. BRAF-KIAA1549 fusion predicts better clinical outcome in pediatric low-grade astrocytoma. Clin. Cancer Res. 17(14), 4790-4798 (2011).

- Shows the important relationship between BK fusion, tumor location and prognosis. 
48. Jacob K, Quang-Khuong D-A, Jones DTW et al. Genetic aberrations leading to MAPK pathway activation mediate oncogene-induced senescence in sporadic pilocytic astrocytomas. Clin. Cancer Res. 17(14), 4650-4660 (2011).

49. Buhl JL, Selt F, Hielscher T et al. The senescence-associated secretory phenotype mediates oncogene-induced senescence in pediatric pilocytic astrocytoma. Clin. Cancer Res. 25(6), 1851-1866 (2019).

50. Jones DTW, Kocialkowski S, Liu L, Pearson DM, Ichimura K, Collins VP. Oncogenic RAF1 rearrangement and a novel BRAF mutation as alternatives to KIAA1549:BRAF fusion in activating the MAPK pathway in pilocytic astrocytoma. Oncogene 28(20), 2119-2123 (2009).

51. Tomić TT, Olausson J, Wilzén A et al. A new GTF2I-BRAF fusion mediating MAPK pathway activation in pilocytic astrocytoma. PLoS ONE 12(4), e0175638 (2017).

52. Sugiura Y, Nagaishi M. Clinical relevance of BRAF status in glial and glioneuronal tumors: a systematic review. J. Clin. Neurosci. 66, 196-201 (2019).

53. Horbinski C. To BRAF or not to BRAF: is that even a question anymore? J. Neuropathol. Exp. Neurol. $72(1), 2-7$ (2013).

54. Hsiao SJ, Karajannis MA, Diolaiti D et al. A novel, potentially targetable TMEM106B-BRAF fusion in pleomorphic xanthoastrocytoma. Cold Spring Harb. Mol. Case Stud. 3(2), a001396 (2017).

55. Antonelli M, Badiali M, Moi L et al. KIAA1549:BRAF fusion gene in pediatric brain tumors of various histogenesis. Pediatr. Blood Cancer 62(4), 724-727 (2015).

56. Sievert AJ, Lang S-S, Boucher KL et al. Paradoxical activation and RAF inhibitor resistance of BRAF protein kinase fusions characterizing pediatric astrocytomas. Proc. Natl Acad. Sci. USA 110(15), 5957-5962 (2013).

57. Miller C, Guillaume D, Dusenbery K, Clark HB, Moertel C. Report of effective trametinib therapy in 2 children with progressive hypothalamic optic pathway pilocytic astrocytoma: documentation of volumetric response. J. Neurosurg. Pediatr. 19(3), 319-324 (2017).

58. Banerjee A, Jakacki RI, Onar-Thomas A et al. A Phase I trial of the MEK inhibitor selumetinib (AZD6244) in pediatric patients with recurrent or refractory low-grade glioma: a Pediatric Brain Tumor Consortium (PBTC) study. Neuro Oncol. 19(8), 1135-1144 (2017).

59. Selt F, Hohloch J, Hielscher T et al. Establishment and application of a novel patient-derived KIAA1549:BRAF-driven pediatric pilocytic astrocytoma model for preclinical drug testing. Oncotarget 8(7), 11460-11479 (2017).

60. Curtin JA, Fridlyand J, Kageshita T et al. Distinct sets of genetic alterations in melanoma. N. Engl. J. Med. 353(20), 2135-2147 (2005).

61. Cancer Genome Atlas Research Network et al.Cancer Genome Atlas Research Network, Weinstein JN, Collisson EA et al. The Cancer Genome Atlas Pan-Cancer analysis project. Nat. Genet. 45(10), 1113-1120 (2013).

62. Hyman DM, Puzanov I, Subbiah V et al. Vemurafenib in multiple nonmelanoma cancers with BRAF V600 mutations. N. Engl. J. Med. 373(8), 726-736 (2015).

63. Schreck KC, Grossman SA, Pratilas CA. BRAF mutations and the utility of RAF and MEK inhibitors in primary brain tumors. Cancers 11(9), 1262 (2019).

-• A detailed review of BRAF mutations in adult primary brain tumors with overview of available and emerging targeted agents.

64. Spagnolo F, Ghiorzo P, Queirolo P. Overcoming resistance to BRAF inhibition in BRAF-mutated metastatic melanoma. Oncotarget 5(21), 10206-10221 (2014).

65. Shih KC, Shastry M, Williams JT et al. Successful treatment with dabrafenib (GSK2118436) in a patient with ganglioglioma. J. Clin. Oncol. 32(29), e98-e100 (2014).

66. Rush S, Foreman N, Liu A. Brainstem ganglioglioma successfully treated with vemurafenib. J. Clin. Oncol. 31(10), e159-160 (2013).

67. Amayiri N, Swaidan M, Al-Hussaini M et al. Sustained response to targeted therapy in a patient with disseminated anaplastic pleomorphic xanthoastrocytoma. J. Pediatr. Hematol. Oncol. 40(6), 478-482 (2018).

68. Weeraratna AT. RAF around the edges-the paradox of BRAF inhibitors. N. Engl. J. Med. 366(3), 271-273 (2012).

69. Robert C, Karaszewska B, Schachter J et al. Improved overall survival in melanoma with combined dabrafenib and trametinib. N. Engl. J. Med. 372(1), 30-39 (2015).

70. Kim KB, Kefford R, Pavlick AC et al. Phase II study of the MEK1/MEK2 inhibitor trametinib in patients with metastatic BRAF-mutant cutaneous melanoma previously treated with or without a BRAF inhibitor. J. Clin. Oncol. 31(4), 482-489 (2013).

71. Touat M, Gratieux J, Condette Auliac S et al. Vemurafenib and cobimetinib overcome resistance to vemurafenib in $B R A F$-mutant ganglioglioma. Neurology 91(11), 523-525 (2018).

72. Yao Z, Gao Y, Su W et al. RAF inhibitor PLX8394 selectively disrupts BRAF dimers and RAS-independent BRAF-mutant-driven signaling. Nat. Med. 25(2), 284-291 (2019).

73. Rauen KA, Schoyer L, McCormick F et al. Proceedings from the 2009 genetic syndromes of the Ras/MAPK pathway: from bedside to bench and back. Am. J. Med. Genet. A 152A(1), 4-24 (2010).

74. Rodriguez EF, Scheithauer BW, Giannini C et al. PI3K/AKT pathway alterations are associated with clinically aggressive and histologically anaplastic subsets of pilocytic astrocytoma. Acta Neuropathol. 121(3), 407-420 (2011). 
75. Dombi E, Baldwin A, Marcus LJ et al. Activity of selumetinib in neurofibromatosis Type 1-related plexiform neurofibromas. N. Engl. J. Med. 375(26), 2550-2560 (2016).

76. Weiss B, Plotkin S, Widemann B et al. NFM-06. NF106: phase II trial of the MEK inhibitor PD -0325901 in adolescents and adults with nf1-related plexiform neurofibromas: an NF clinical trials consortium study. Neuro Oncol. 20(Suppl. 2), i143-i143 (2018).

77. Nagasaka M, Li Y, Sukari A, Ou S-HI, Al-Hallak MN, Azmi AS. KRAS G12C Game of Thrones, which direct KRAS inhibitor will claim the iron throne? Cancer Treat. Rev. 84, 101974 (2020).

78. Rivera B, Gayden T, Carrot-Zhang J et al. Germline and somatic FGFR1 abnormalities in dysembryoplastic neuroepithelial tumors. Acta Neuropathol. 131(6), 847-863 (2016).

79. Pathak P, Kumar A, Jha P et al. Genetic alterations related to BRAF-FGFR genes and dysregulated MAPK/ERK/mTOR signaling in adult pilocytic astrocytoma: genetic alterations in adult pilocytic astrocytoma. Brain Pathol. 27(5), 580-589 (2017).

80. Brastianos PK, Ippen FM, Hafeez U, Gan HK. Emerging gene fusion drivers in primary and metastatic central nervous system malignancies: a review of available evidence for systemic targeted therapies. Oncologist 23(9), 1063-1075 (2018).

81. Di Stefano AL, Fucci A, Frattini V et al. Detection, characterization, and inhibition of FGFR-TACC fusions in IDH wild-type glioma. Clin. Cancer Res. 21(14), 3307-3317 (2015).

82. Cocco E, Scaltriti M, Drilon A. NTRK fusion-positive cancers and TRK inhibitor therapy. Nat. Rev. Clin. Oncol. 15(12), 731-747 (2018).

83. Louis DN, Wesseling P, Aldape K et al. cIMPACT-NOW update 6: new entity and diagnostic principle recommendations of the cIMPACT-Utrecht meeting on future CNS tumor classification and grading. Brain Pathol. 30(4), 844-856 (2020).

84. Reis GF, Pekmezci M, Hansen HM et al. CDKN2A loss is associated with shortened overall survival in lower-grade (World Health Organization Grades II-III) astrocytomas. J. Neuropathol. Exp. Neurol. 74(5), 442-452 (2015).

85. Rodriguez FJ, Scheithauer BW, Burger PC, Jenkins S, Giannini C. Anaplasia in pilocytic astrocytoma predicts aggressive behavior. Am. J. Surg. Pathol. 34(2), 147-160 (2010).

86. Ebrahimi A, Skardelly M, Schuhmann MU et al. High frequency of H3 K27M mutations in adult midline gliomas. J. Cancer Res. Clin. Oncol. 145(4), 839-850 (2019).

87. Colin C, Padovani L, Chappé C et al. Outcome analysis of childhood pilocytic astrocytomas: a retrospective study of 148 cases at a single institution. Neuropathol. Appl. Neurobiol. 39(6), 693-705 (2013).

88. Kleinschmidt-DeMasters BK, Donson AM, Vogel H, Foreman NK. Pilomyxoid astrocytoma (PMA) shows significant differences in gene expression vs. pilocytic astrocytoma (PA) and variable tendency toward maturation to PA. Brain Pathol. 25(4), 429-440 (2015).

89. Rodriguez FJ, Schniederjan MJ, Nicolaides T, Tihan T, Burger PC, Perry A. High rate of concurrent BRAF-KIAA1549 gene fusion and 1p deletion in disseminated oligodendroglioma-like leptomeningeal neoplasms (DOLN). Acta Neuropathol. 129(4), 609-610 (2015).

90. Appay R, Pages M, Colin C, Jones DTW, Varlet P, Figarella-Branger D. Diffuse leptomeningeal glioneuronal tumor: a double misnomer? A report of two cases. Acta Neuropathol. Commun. 8(1), 95 (2020).

91. Capper D, Stichel D, Sahm F et al. Practical implementation of DNA methylation and copy-number-based CNS tumor diagnostics: the Heidelberg experience. Acta Neuropathol. 136(2), 181-210 (2018).

92. Jaunmuktane Z, Capper D, Jones DTW et al. Methylation array profiling of adult brain tumours: diagnostic outcomes in a large, single centre. Acta Neuropathol. Commun. 7(1), 24 (2019).

93. Reuss DE, Kratz A, Sahm F et al. Adult IDH wild type astrocytomas biologically and clinically resolve into other tumor entities. Acta Neuropathol. 130(3), 407-417 (2015).

94. Saunders DE, Phipps KP, Wade AM, Hayward RD. Surveillance imaging strategies following surgery and/or radiotherapy for childhood cerebellar low-grade astrocytoma. J. Neurosurg. 102(Suppl. 2), 172-178 (2005).

95. Ishkanian A, Laperriere NJ, Xu W et al. Upfront observation versus radiation for adult pilocytic astrocytoma. Cancer 117(17), 4070-4079 (2011).

96. Brown PD, Anderson SK, Carrero XW et al. Adult patients with supratentorial pilocytic astrocytoma: long-term follow-up of prospective multicenter clinical trial NCCTG-867251 (Alliance). Neuro Oncol. Pract. 2(4), 199-204 (2015).

97. Parsa CF, Givrad S. Juvenile pilocytic astrocytomas do not undergo spontaneous malignant transformation: grounds for designation as hamartomas. Br. J. Ophthalmol. 92(1), 40-46 (2008).

98. Hayashi S, Akao N, Nakazato Y, Okamoto K. Pilocytic astrocytoma with anaplasia arising from the optic chiasm in a very elderly patient. Neurology 89(17), 1840 (2017).

99. Carabenciov ID, Bhargav AG, Uhm JH, Ruff MW. Bevacizumab use in refractory adult pilocytic astrocytoma: a single-center case series. Neurologist 24(3), 87-89 (2019).

100. Packer RJ, Ater J, Allen J et al. Carboplatin and vincristine chemotherapy for children with newly diagnosed progressive low-grade gliomas. J. Neurosurg. 86(5), 747-754 (1997). 
101. Gnekow AK, Walker DA, Kandels D et al. A European randomised controlled trial of the addition of etoposide to standard vincristine and carboplatin induction as part of an 18-month treatment programme for childhood ( $\leq 16$ years) low grade glioma - A final report. Eur. J. Cancer 81, 206-225 (2017).

102. Bouffet E, Jakacki R, Goldman S et al. Phase II study of weekly vinblastine in recurrent or refractory pediatric low-grade glioma. J. Clin. Oncol. 30(12), 1358-1363 (2012).

103. Xue JY, Lito P. Quest for Clinically Effective RAF Dimer Inhibitors. J. Clin. Oncol. 38(19), 2197-2200 (2020).

104. Hargrave DR, Bouffet E, Tabori U et al. Efficacy and safety of dabrafenib in pediatric patients with BRAF V600 mutation-positive relapsed or refractory low-grade glioma: results from a phase I/IIa study. Clin. Cancer Res. 25(24), 7303-7311 (2019).

105. Jones DTW, Kieran MW, Bouffet E et al. Pediatric low-grade gliomas: next biologically driven steps. Neuro Oncol. 20(2), 160-173 (2018).

106. Selt F, van Tilburg CM, Bison B et al. Response to trametinib treatment in progressive pediatric low-grade glioma patients. J. Neurooncol. 149(3), 499-510 (2020).

107. Fangusaro J, Onar-Thomas A, Young Poussaint T et al. Selumetinib in paediatric patients with BRAF-aberrant or neurofibromatosis type 1-associated recurrent, refractory, or progressive low-grade glioma: a multicentre, Phase II trial. Lancet Oncol. 20(7), 1011-1022 (2019).

108. Zhang C, Spevak W, Zhang Y et al. RAF inhibitors that evade paradoxical MAPK pathway activation. Nature 526(7574), 583-586 (2015).

109. Sen $S$, Tanaka R, Khatua $S$ et al. Dual inhibition of BRAF and mTOR in $B R A F^{V 600 E}$-mutant pediatric, adolescent, and young adult brain tumors. Mol. Case Stud. 6(4), a005041 (2020).

110. Green R, Woyshner E, Quan J, Pope W, Cloughesy T. Treatment of unresectable adult pilocytic astrocytoma with bevacizumab with or without temozolomide (P01.097). Neurology 80(Suppl. 7), P01.097 (2013).

111. Wasilewski A, Mohile N. Durable response to bevacizumab in adults with recurrent pilocytic astrocytoma. CNS Oncol. 7(3), CNS26 (2018).

112. Theeler BJ, Ellezam B, Yust-Katz S, Slopis JM, Loghin ME, de Groot JF. Prolonged survival in adult neurofibromatosis type I patients with recurrent high-grade gliomas treated with bevacizumab. J. Neurol. 261(8), 1559-1564 (2014). 